\title{
Erratum to: Biochemical biomarker responses to pollution in selected sentinel organisms across the Eastern Mediterranean and the Black Sea
}

\author{
Catherine Tsangaris ${ }^{1}$ - Vanessa Moschino ${ }^{2} \cdot$ Evangelia Strogyloudi $^{1} \cdot$ Valentina Coatu $^{3}$. \\ Andreja Ramšak ${ }^{4}$ - Rana Abu Alhaija ${ }^{5}$ - Susana Carvalho ${ }^{6}$ - Serena Felline ${ }^{7}$. \\ Alisa Kosyan $^{8}$ - Yiota Lazarou ${ }^{9}$ - Ioannis Hatzianestis ${ }^{1} \cdot$ Andra Oros $^{3} \cdot$ Daniela Tiganus $^{3}$
}

Published online: 29 September 2016

(C) Springer-Verlag Berlin Heidelberg 2016

Erratum to: Environ Sci Pollut Res (2016) 23:1789-1804

DOI 10.1007/s11356-015-5410-x

The names of the authors have been published incorrectly.

The correct order of the Author names are shown in this paper.

The online version of the original article can be found at http://dx.doi. org/10.1007/s11356-015-5410-x.

Catherine Tsangaris

ctsangar@hcmr.gr

1 Institute of Oceanography, Hellenic Center for Marine Research, 46.7 km, Athinon-Souniou Ave., P.O. Box 712,

19013 Anavyssos, Greece

2 Institute of Marine Sciences-ISMAR-CNR, Arsenale, Castello, 2737f, 30122 Venezia, Italy

3 National Institute for Marine Research and Development "Grigore Antipa”, Bvd. Mamaia 300, 900581 Constanta 3, Romania

4 National Institute of Biology, Marine Biology Station, Fornače 41, 6330 Piran, Slovenia
5 Energy, Environment and Water Research Center (EEWRC), The Cyprus Institute, 20 Konstantinou Kavafi, 2121 Aglanzia, P.O. Box 27456, 1645 Nicosia, Cyprus

6 KAUST - King Abdullah University of Science and Technology, Red Sea Research Center, Thuwal 23955-6900, Saudi Arabia

7 Laboratory of Zoology and Marine Biology, Department of Biological and Environmental Science and Technologies, University of Salento, Provincial road Lecce-Monteroni, 73100 Lecce, Italy

8 Laboratory of Ecology and Morphology of Marine Invertebrates, A. N. Severtsov Institute of Ecology and Evolution, Russian Academy of Sciences, Leninsky prospect 33, 119071 Moscow, Russia

9 Oceanography Centre, University of Cyprus, P.O. Box 20537, 1678 Nicosia, Cyprus 